\title{
The clinical spectrum of reactions developed based on paraphenylenediamine hypersensitivity two pediatric
} cases

\author{
${ }^{1}$ Clinics of Pediatrics, Bagcilar Training and Research Hospital, Istanbul, Turkey \\ Head of the Clinics: Özgül Yigit MD \\ ${ }^{2}$ Clinics of Pediatrics, Istanbul Medipol University Hospital, Istanbul, Turkey \\ Head of the Clinics: Prof. Ayhan Tastekin MD \\ ${ }^{3}$ Department of Pediatric Allergy, Dr Behcet Uz Children's Hospital, Izmir, Turkey \\ Head of the Department: Prof. Demet Can MD
}

Hikmet Tekin Nacaroglu¹, Sinan Yavuz¹, Eray Basman², Semiha Bahceci ${ }^{3}$, Mehmet Tasdemir ${ }^{1}$, Özgül Yigit ${ }^{1}$, Demet Can $^{3}$

Postep Derm Alergol 2015; XXXII (5): 393-395 DOI: 10.5114/pdia.2015.52738

Paraphenylenediamine (PPD) is a blue-black aniline dye commonly used in hair dyes. It is also used in textile and fur dyes, wool dye, dark cosmetics, temporary tattoo hennas, photo baths, and photocopy and printing ink. Paraphenylenediamine, which accelerates the absorption of hair dye and henna tattoos by the skin and helps the formation of the black color, is an allergen. Paraphenylenediamine leads to hypersensitivity reactions, involving allergic and irritant contact dermatitis [1-3]. Since tattoo and hair dyes are now frequently used in younger children, complications of these applications (which are considered harmless and temporary) are appearing in children. In this study, two pediatric patients who presented to our department with clinical symptoms similar to angioedema and allergic contact dermatitis are discussed.

Case 1: A 9-year-old boy presented with redness, itching, swelling and burning sensation in his right arm. In the preliminary case history, he stated he had received a temporary tattoo performed with Indian henna on his right arm 3 days before. There was no atopy history of either the patient or his family. He had no systemic or dermatological illnesses. On the dermatological examination, erythematous and edematous papulonodular plaques in the tattooed area of the right arm were observed (Figure 1 A). Other systemic findings and laboratory tests were within normal limits. He was diagnosed with allergic contact dermatitis based on the temporary Indian henna tattoo and prescribed topical corticosteroid for 5 days and oral desloratadine $5 \mathrm{mg}$ /day for 5 days. The lesions improved without sequelae within a short period of time (Figure $1 \mathrm{~B}$ ).
Case 2: A 14-year-old girl presented to our clinic with edematous eyes, and redness and swelling in the scalp and nape area. The patient reported that she had not used any new cosmetic products or medicines for the area in which lesions were located; however, she had her hair dyed only 2 days before the complaints started. She had no atopy and no chronic skin disease in her preliminary case history, but it was discovered that the redness and itching developed after she had received a temporary Indian henna tattoo on her arm 2 months before. On the physical examination, hyperemia and edema were observed on her face and swelling that could have been angioedema in her both eyelids (Figure $2 \mathrm{~A}$ ). Hyperemia and edema were diagnosed in her scalp and nape area. She had no respiratory problems. Other systemic examination findings and laboratory tests were within normal limits. She was prescribed desloratadine antihistamine treatment $5 \mathrm{mg} /$ day orally and systemic corticosteroid therapy $1 \mathrm{mg} / \mathrm{kg} /$ day for 5 days with allergic contact dermatitis diagnosis similar to angioedema and lesions improved within 10 days with no sequelae (Figure 2 B). Six weeks after clinical recovery had been achieved, the European standard patch test (TRUE Test; Smart Practice Denmark ApS, Hillerød, Denmark) series and the patch test were conducted. At the 48, 72, and $96 \mathrm{~h}$ time points, +1 sensitivity to PPD were seen in both cases (Figures $1 \mathrm{C}$ and $2 \mathrm{C}$ ). The patients were warned about the use of hair dye and black henna tattoos containing PPD and similar derivatives. A list of products that included PPD and that are cross-reactive with PPD was given to the patients.

Address for correspondence: Hikmet Tekin Nacaroglu MD, Clinics of Pediatrics, Bagcilar Training and Research Hospital, Istanbul, Turkey, phone: +90 505649 2917, fax: +90 21244042 52, e-mail: tekin212@gmail.com

Received: 21.11.2014, accepted: 25.12.2014. 

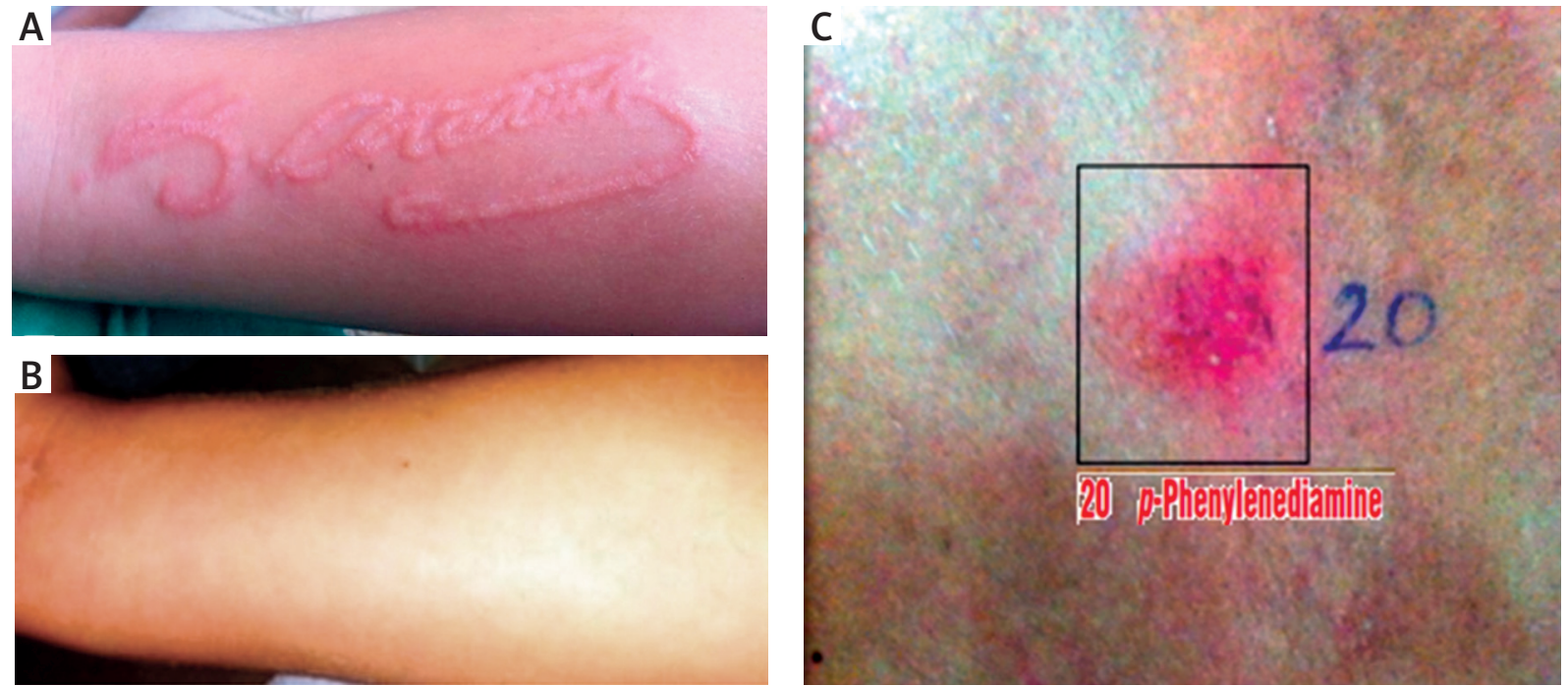

Figure 1. A - Erythematous, edematous, papulonodular lesions in the tattoo area. B - Appearance after treatment. $C-A$ result of the patch test +1 reaction (erythema, edema, infiltration)
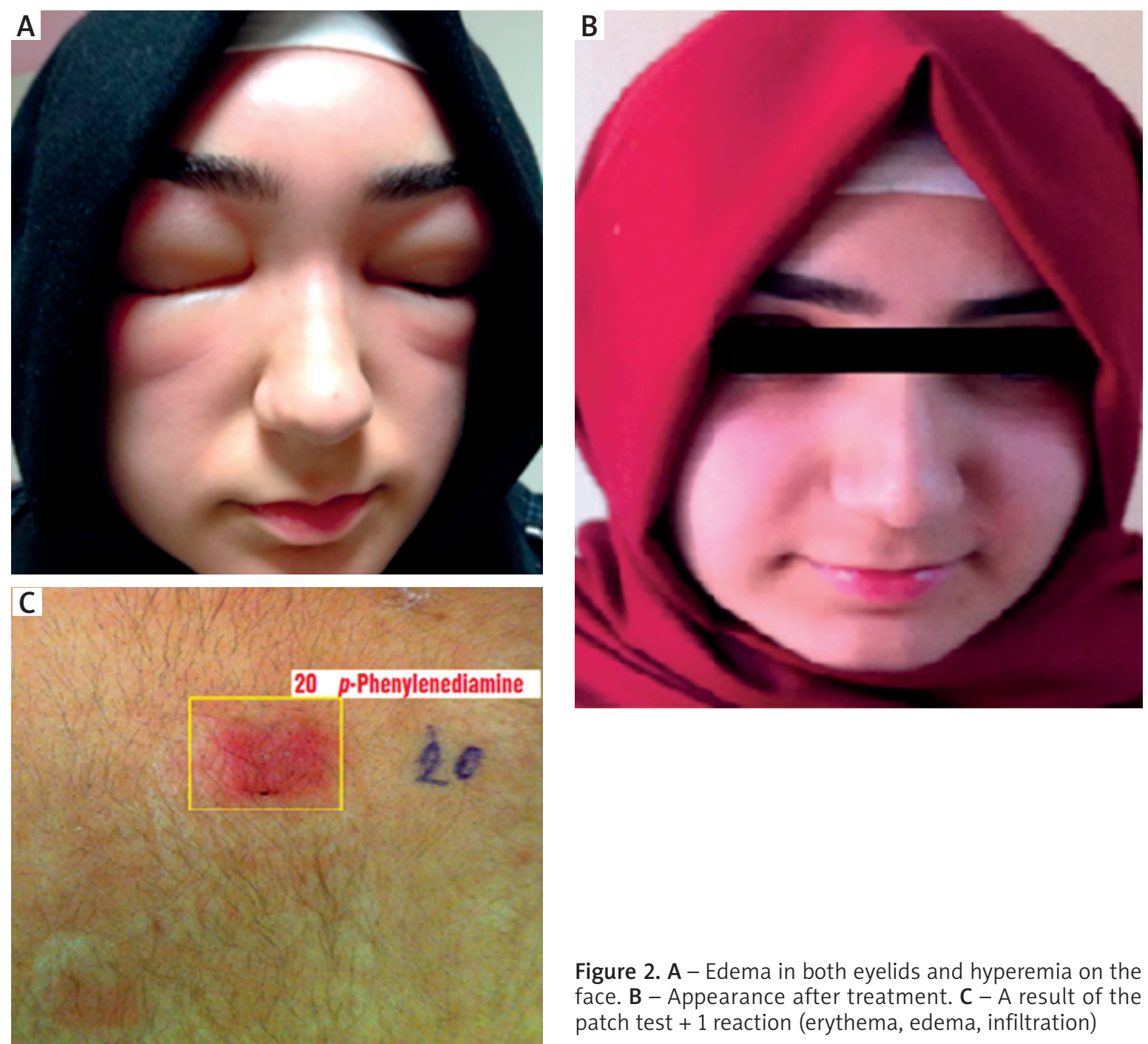

Figure 2. A - Edema in both eyelids and hyperemia on the face. $\mathrm{B}$ - Appearance after treatment. $\mathrm{C}-\mathrm{A}$ result of the patch test +1 reaction (erythema, edema, infiltration) 
Paraphenylenediamine is a powerful allergen. It may be responsible for several hypersensitivity reactions especially allergic and irritant contact dermatitis. Hair dyes, textile dyes, latex, shoe polish, tattoo, etc., include PPD [1]. Although natural henna is harmless, PPD is frequently used to increase the dyeing potential by intensifying the color of the henna. Active hypersensitivity has developed against PPD used in temporary tattoos and relevant components. In a population who underwent the patch test in Europe, PPD hypersensitivity prevalence was reported as $0.1-1 \%$ [4]. The PPD concentration in black henna tattoos is $15.7 \%$ which is higher than its concentration in hair dyes. If these high-dose PPD concentrations cannot be neutralized, they cause powerful PPD hypersensitivity with longer-term skin contact. As a result, recurrent PPD exposure leads to delayed-type 4 excessive hypersensitivity reactions such as acute contact dermatitis even in lower doses in hair dyes [4]. In the second case, there was a sensitization history due to the temporary henna tattoo performed 2 months before.

Acute effects observed after high-dose PPD exposure were reported such as eye irritation, severe dermatitis, kidney failure, asthma, gastritis, convulsion, vertigo, tremor, and coma [4]. Other dermatological lesions apart from contact dermatitis depending on PPD include erythema multiforme, bullous contact dermatitis, Wells' syndrome (eosinophilic cellulitis), exudative erythema, itchy, edematous, erythematous patch and plaque, and sometimes vesicular lesions [5, 6]. Cases in the literature have been reported that allergic contact dermatitis following the hair dye process cause symptoms similar to angioedema [1, 4]. Contact dermatitis related to PPD in hair dyes typically spread to the forehead, neck, eyelids, and face from the scalp. Owing to hair dye involving PPD, cases with severe scalp and upper respiratory edema and hair loss on the scalp have been reported in the literature [7]. Although allergic contact dermatitis developed after the temporary henna tattoo in our first patient, angioedema was observed in our second patient characterized by swelling in the lower and upper eyelids and beneath the scalp. Paraphenylenediamine hypersensitivity was confirmed by patch tests in both cases.

Topical steroids and antihistamines are usually sufficient for treatment, but sometimes short-term systemic corticosteroid use is also required. In the first case, lesions regressed with topical steroid cream and oral antihistaminic treatment and in the second one with short-term corticosteroid and oral antihistaminic treatment. According to the literature, post-inflammatory hypopigmentation or hyperpigmentation has been observed in the location of the tattoo following the treatment, and even keloid scar formation has been reported after severe contact dermatitis [8]. Our patients' lesions improved without sequelae.

Thus, since hair dyes and temporary henna tattoos are widely used by children today, PPD hypersensitivity should be considered in reactions that develop after such practices. In patients exposed to paraphenylenediamine, early diagnosis and taking precautions are important for hypersensitivity reactions.

\section{Conflict of interest}

The authors declare no conflict of interest.

\section{References}

1. Tukenmez Demirci G, Kivanc Altunay I, Atis G, Kucukunal A. Allergic contact dermatitis mimicking angioedema due to paraphenylendiamine hypersensitivity: a case report. Cutan Ocul Toxicol 2012; 31: 250-2.

2. Wojciechowska M, Czajkowski R, Kowaliszyn B, et al. Analysis of skin patch test results and metalloproteinase-2 levels in a patient with contact dermatitis. Postep Derm Alergol 2015; 32: 154-61.

3. Zukiewicz-Sobczak WA, Adamczuk P, Wróblewska P, et al. Allergy to selected cosmetic ingredients. Postep Derm Alergol 2013; 30: 307-10.

4. Haluk Akar H, Adatepe S, Tahan F, Solmaz I. Hair dyes and temporary tattoos area real hazard for adolescents? Eur Ann Allergy Clin Immunol 2014; 46: 35-7.

5. Jovanovic DL, Slavkovic-Jovanovic MR. Allergic contact dermatitis from temporary henna tattoo. J Dermatol 2009; 36: 63-5.

6. Nacaroglu HT, Celegen M, Unsal Karkiner CS, et al. Eosinophilic cellulitis (Wells' syndrome) caused by a temporary henna tattoo. Postep Derm Alergol 2014; 31: 322-4.

7. Ishida W, Makino T, Shimizu T. Severe hair loss of the scalp due to a hair dye containing paraphenylenediamine. ISRN Dermatol 2011; 947284.

8. Marcoux D, Couture-Trudel PM, Rboulet-Delmas G, Sasseville $D$. Sensitization to paraphenylenediamine from a street side temporary tattoo. Pediatr Dermatol 2002; 19: 49. 